Revista Digital Universitaria

Vol. 20, Núm. 5, septiembre-octubre 2019

\title{
Cambios y adaptaciones: lecciones desde la tecnología, la cultura y la biología
}

Equipo editorial

Entre la gran cantidad de cambios que vivimos en la actualidad, se pueden detectar un sinfín de adaptaciones, unas a nivel biológico, otros a nivel cultural, social y hasta individual. En este número de la revista se exploran diferentes procesos adaptivos que podemos observar desde el mundo microbiano y los antibióticos, hasta la respuesta de las instituciones de educación superior a los retos ambientales; de los algoritmos criptográficos a la escritura de graffiti. Partimos de la premisa de que los acontecimientos que experimentamos requieren de una constante adecuación, por lo tanto, te invitamos a conocer y reflexionar, a partir de los diferentes artículos presentados en este número, las propuestas que presentan los autores ante las problemáticas abordadas en cada texto.

Comencemos con la sección Varietas cuyo primer artículo, "De biofilms y otras películas", narra cómo, de la misma manera que un grupo multidisciplinario de seres humanos se organiza para hacer una película, los microorganismos se agrupan para formar placas, delgadísimas películas, en donde el todo es más que la suma de las partes, ya que cada bacteria, arquea, hongo o protista involucrado "actúa" en un papel específico. Los autores nos comparten qué son los biofilms, cómo están hechos, cuáles son sus funciones, así como sus implicaciones para los seres humanos, especialmente en procesos de salud-enfermedad. Por otra parte, te preguntarás por qué hasta hace poco tiempo se empezó a conocer con mayor detalle estas asociaciones microbianas, lo cual se ha debido a que no contábamos con los instrumentos necesarios para estudiarlos.

Probablemente has escuchado alguna noticia en la que se menciona la existencia de bacterias resistentes a los antibióticos, las recomendaciones médicas de no automedicarte, o bien de concluir el tratamiento médico tal como fue prescrito. A través del artículo "Resistencia a antibióticos: cuando nuestro armamento se torna ineficiente" podrás ahondar en este interesante tema, pues debido al mal uso que se ha hecho del consumo de antibióticos, hemos propiciado que las bacterias generen ciertos mecanismos de resistencia. Explora en este artículo los matices e implicaciones sobre el tema, así como las indicaciones a seguir.

DOI: http://doi.org/10.22201/codeic.16076079e.2019.v20n5.a0.

Universidad Nacional Autónoma de México, Coordinación de Desarrollo Educativo e Innovación Curricular (CODEIC) 
La idea del desarrollo sustentable es resultado de una cadena de causas y consecuencias. Seguramente estás consciente de que la industrialización generó una sobreexplotación de recursos naturales, lo que, a su vez, ha provocado una mayor emisión de gases contaminantes, la destrucción de la capa de ozono, el efecto invernadero y, con ello, la crisis ambiental en la que nos encontramos. Como una adecuación positiva ante esta trágica serie de acontecimientos, el texto: "El desarrollo sustentable en las instituciones de educación superior. Un verdadero desafío", explora el papel que dichas instituciones pueden jugar para alcanzar los objetivos de desarrollo sustentable sugeridos por la ONU.

Otra de las consecuencias de la crisis ambiental radica en la destrucción de ecosistemas y hábitats de diversas especies, entre ellas se encuentra la Rata de Magdalena, de la cual quizá no has escuchado. En el artículo: "Rata de Magdalena: un importante mamífero mexicano, poco conocido y en riesgo de extinción", los autores nos comparten una amplia información sobre este animal endémico, sus características, sus hábitos, los lugares en los que vive. El propósito es, además de dar a conocer a esta especie, lograr que se propongan acciones para su conservación.

Haciendo un recorrido por la tecnología que permite enviar y recibir información, nos adentramos en la criptografía como un método para proteger las comunicaciones mediante el uso de códigos, de modo que sólo aquellos a quienes se destina dicha información puedan leerla y procesarla. En los últimos tiempos, la criptografía se ha convertido en un importante campo de batalla entre algunos de los mejores matemáticos e informáticos del mundo, pues implica la llegada de un nuevo paradigma en el cual la computación cuántica resulta en una amenaza a la capacidad de almacenar y transferir, de manera segura, información confidencial; ante esta situación, se están diseñando nuevos algoritmos y estándares. Conoce este tema en el artículo "Un acercamiento a la línea del tiempo de los algoritmos criptográficos" y descubre el conjunto de desafíos que estarán enfrentando los algoritmos del futuro, también llamados postcuánticos.

Las transformaciones en los algoritmos de codificación no sólo se han dado en lo que respecta a la criptografía, también ocurren en nuestros celulares. De esta manera, los desarrolladores web tuvieron que pasar de las pantallas de escritorio a las aplicaciones móviles y, en este contexto, surge la necesidad de utilizar un sólo lenguaje de programación tanto para iOS como para Android. Una adaptación creada ante esta necesidad es React Native, una librería que permite crear aplicaciones móviles usando sólo JavaScript. Adéntrate en este tema leyendo el artículo: "React Native: acortando las distancias entre desarrollo y diseño móvil multiplataforma".

¿Te has preguntado qué papel juegan los medios de comunicación en la niñez?, ¿sabías que el Programa Nacional de Protección de Niñas, Niños y Adolescentes 2016-2018 establece que se debe garantizar la generación de contenidos desde el enfoque de sus derechos en los medios de comunicación? En el artículo "Medios de comunicación en la protección de la infancia: una lección que aprender", las autoras plantean una serie de reflexiones con respecto al papel de los medios de comunicación y el impacto formativo que estos tienen en los elementos culturales y sociales en la infancia. Además, establecen que los medios de comunicación deben trabajar como un engrane más del sistema de defensa de derechos de niñas, niños y adolescentes. 
En muchas ocasiones, mientras recorres el lugar en donde vives has visto graffitis. En esta ocasión también los encontrarás en la sección Caleidoscopio, en la que el autor habla de estas formas de expresión como afirmaciones de puntos de vista y proclamas políticas. En el contexto del graffiti el estímulo se vuelve efecto, es a la vez respuesta y provocación, especialmente en el texto "Estéticas de la Calle. 7ª edición de un congreso transdisciplinario", donde el graffiti se vuelve el objeto de estudio, pasa del margen al centro.

Probablemente has sentido la necesidad de hacer algo diferente, de trazar tu propio camino. La vida no se trata sólo de lo que ves y haces en tu propio país, ciudad natal, escuela o incluso con tus amigos. ¿Qué hay más allá? En la sección Continuum educativo Luis Alberto Sandoval y Vianey Santiago te platicarán, en el artículo "Explorar la movilidad estudiantil: Facultad de Filosofía y Letras de la UNAM", el panorama del intercambio académico en su Facultad; en el descubrirás las distintas modalidades, los países y las principales instituciones a las acuden los alumnos de intercambio académico. Además, los autores analizan las oportunidades, la importancia y los beneficios que implica la movilidad estudiantil, pues convertirse en un estudiante de intercambio brinda más que conocimiento sobre otro país, su idioma y su cultura; vivir en el extranjero te enseña a construir amistades, asumir la responsabilidad de tí mismo, respetar las diferencias y tolerar las creencias de los demás.

Siguiendo con la temática de enseñanza-aprendizaje, nos preguntamos: ¿Cuáles son los medios tecnológicos que utilizas cuando enseñas o aprendes? ¿Consideras el uso de las TIC en el aprendizaje como una ventaja o una desventaja? ¿En verdad las TIC tienen un impacto en el proceso de enseñanza-aprendizaje? En la sección Universidades podrás averiguar la conclusión a la que llegaron los autores del artículo "Aplicando las TIC en el aprendizaje de la enfermería profesional en pro de su rendimiento académico". Descubrirás que pese a que hoy contamos con mayor disponibilidad y apoyo a la integración de las TIC en las actividades de enseñanzaaprendizaje, también es cierto que hay una barrera que tiene que ver con la habilidad para manejar estas herramientas y el acceso a internet.

Esperamos que disfrutes este número de la Revista Digital Universitaria. Cada artículo seleccionado para esta entrega busca acercarnos a los principios, las teorías y los avances en cada una de sus áreas. De esta manera, te presentamos un número variado que nos muestra diversos escenarios de conocimiento que los autores dibujaron para todos nosotros. Si eres de los que gusta de estar informado, date permiso para relajarte y gozar los textos aquí reunidos. La RDU es la provocación, tú, lector, determinarás los cambios.

\section{Cómo citar este artículo}

* Gálvez García, Carina Itzel, del Ángel Martínez, Rosa María y Carranco Arenas, Morgana Paola (2019). De cambios y adaptaciones: lecciones desde la tecnología, la cultura y la biología. Revista Digital Universitaria (RDU). Vol. 20, núm. 5 septiembre-octubre. DOI: http://doi.org/10.22201/ codeic.16076079e.2019.v20n5.a0.

Universidad Nacional Autónoma de México, Coordinación de Desarrollo Educativo e Innovación Curricular (CODEIC) 